\title{
Italian family paediatricians' approach and management of celiac disease: a cross-sectional study in Puglia Region, 2012
}

Francesca Fortunato ${ }^{1}$, Domenico Martinelli ${ }^{1}$, Vanessa Cozza ${ }^{1}$, Pierpaolo Ciavarella ${ }^{1}$, Anna Valente ${ }^{2}$, Teresa Cazzato ${ }^{2}$, Ruggiero Piazzolla ${ }^{2}$, Rosa Prato ${ }^{1 *}$ and Biagio Pedalino ${ }^{1}$

\begin{abstract}
Background: Celiac disease (CD) is a chronic autoimmune illness of the small intestine triggered by gluten consumption in genetically predisposed individuals. CD presentation is not limited to the gastrointestinal tract and it is still under-diagnosed. Complete resolution of clinical manifestations follows if a gluten-free diet is adopted. In western countries, CD prevalence is approximately 1\%. Age of onset is often between 6 months and 7 years. We assessed the approach to diagnosis and management of celiac patients by the paediatricians in Puglia Region, Italy.
\end{abstract}

Methods: We conducted a cross-sectional survey among the 589 Apulian Family Paediatricians (FPs) during January 2011-January 2012 using a self-administered web-based standardized questionnaire including self-assessment of their knowledge, diagnostic path and type of management they would follow for $C D$, clinical information on their celiac patients. We assessed associations among the explored variables by defining double-entry contingency tables and calculating Odds Ratio (OR) with 95\% Confidence Intervals (Cls).

Results: The 218 (37\%) FPs participating in the study reported 1,020 CD patients (representing approximately 1\% of the child population covered by the enrolled FPs). Of them, 55\% were female; $45 \%$ were aged 5-10 years. Weight loss and stunting were the main reported symptoms at diagnosis (41\%). The majority (98\%) of FPs requested anti-transglutaminase antibody (tTG-Ab) titres for CD diagnosis. Approximately $78 \%$ of FPs recommended gluten introduction in the diet of infants at the age of 6 months; $12 \%$ and $8 \%$ recommended introduction of gluten before and after 6 months of age respectively.

The degree of knowledge for either CD diagnosis making process or CD related diseases was medium/high in 97\% and 82\% of the participating FPs respectively. FPs (83\%) who had a medium or high degree of knowledge of CD patients' diet were more likely to experience low or no difficulty in providing their patients with dietary advices (OR:5.5; 95\% Cl:1.7-17.5).

Conclusions: Apulian FPs report a good degree of knowledge of CD, its diagnosis and its management. We will diffuse results and recommendations to all paediatricians in the Region. Actions aiming to continued education on CD in medical under and postgraduate trainings are crucial to prevent under-diagnosis.

Keywords: Celiac disease, Knowledge attitude and practice, Paediatricians

\footnotetext{
* Correspondence: rosa.prato@unifg.it

'Department of Medical and Surgical Sciences, University of Foggia, Viale Pinto, 71100 Foggia, Italy

Full list of author information is available at the end of the article
} 


\section{Background}

Celiac disease (CD) is a chronic autoimmune illness of the small intestine triggered by gluten consumption in genetically predisposed individuals. In these individuals, exposure to gluten produces mucosal damage that, following different stages of disease severity, may result in small-intestinal mucosal atrophy. CD clinical manifestations are not limited to the gastrointestinal tract and systemic signs can be commonly associated (i.e. anemia, osteoporosis, short stature, arthritis, infertility, peripheral neuropathy and dermatitis herpetiformis) [1-5]. A complete resolution of the clinical manifestations and of the intestinal mucosal lesions is obtained if a gluten-free diet is adopted [6]. However, $\mathrm{CD}$ is still heavily underdiagnosed, approximately $75-90 \%$ of the celiac population in western countries remains unrecognized, presumably due to the absence, or the atypical nature of symptoms, but also as a consequence of the poor physician awareness of the clinical spectrum of the disease $[7,8]$.

In western countries, the prevalence of $\mathrm{CD}$ in the general population is approximately $1 \%$ and the female:male ratio of 2:1 [1,2,7,9,10]. Recent US and European studies show however a 2-4.5 fold increase in the disease prevalence [11-13]. In Italy, CD prevalence is between $0.55 \%$ and $1 \%[14]$.

The age of onset of $\mathrm{CD}$ is often between 6 months and 7 years (the median age when $\mathrm{CD}$ antibody markers develop is 3 years) [15]. Prevalence is higher among risk patients, i.e. type 1 diabetes mellitus (varying from 3 to 6\%) and first-degree relatives of celiac patients (up to 20\%) [16].

Anti-transglutaminase Antibody (tTG-Ab) and Endomysial Antibody (EMA-Ab) are the most frequently used serological tests although Anti-gliadin Antibody (AGA-Ab) measurement is also available. In dubious cases, genetic testing is now used to exclude diagnosis [17]. According to the European Society of Paediatric Gastroenterology, Hepatology, and Nutrition (ESPGHAN) guidelines, a control biopsy is considered mandatory for asymptomatic patients at first presentation or those with equivocal response to the diet to verify the effects of the gluten-free diet on the architecture of the intestinal mucosa. Gluten challenge is advisable when the initial diagnosis or the clinical response to a gluten-free diet is uncertain. Furthermore, the ESPGHAN guidelines recommend gluten challenge, preceded by HLA typing and assessment of mucosal histology and discouraged before the child is 5 years old $[17,18]$. According to ESPGHAN and EFSA (European Food Safety Authority) introduction of solid foods in the diet of infants before the end of the 3rd month of life should be avoided as children might develop food allergies [19-24].

In Italy, by law, every child is included in the list of patients of a Family Paediatrician (FP) from birth until the age of fourteen years. In case of specific illnesses or disabilities, assistance may be extended up to the age of
16 years. Normally, the number of children included in the list of the FPs is known to the public and can reach a maximum of 800 children; a number of exceptions are accepted, i.e. lack of paediatricians in the territory, a new child in a family with other children followed up by the same paediatrician $[25,26]$. FPs' role is to follow up their patients in terms of regular check up and monitor their growth, provide advices for the maintenance of their health wellbeing, suggest the necessary diagnostic tests to identify diseases, prescribe proper treatment and support families for the best management of their children chronic diseases [27].

We described the knowledge of $\mathrm{CD}$, approach to diagnosis and management of the celiac patient by the paediatricians in Puglia Region, Italy.

\section{Methods}

We conducted a cross-sectional study among the 589 Apulian FPs during the period January 2011 - January 2012. We invited all FPs by email sending them an explanatory letter introducing the study and its objectives and the link to a self-administered web-based standardized questionnaire (www.surveymonkey.com) including demographics and province of work of the paediatricians, clinical information on their celiac patients (i.e. clinical presentation at diagnosis), self-assessment of their knowledge, attitude, diagnostic path and type of management they would follow for $\mathrm{CD}$. We sent weekly reminders to non-respondents.

We assessed the possible associations among the explored variables by defining double-entry contingency tables and calculating Odds Ratio (OR) with 95\% CIs. The assessment of significant differences across the means of continuous variables relied on the $t$-test for independent samples considering as significant those values with $\mathrm{p}<0.05$. We used STATA-MP software, version 10.1 for Mac OS X.

\section{Ethics statement}

The study received the approval by the Institutional Review Board of the Puglia (Italy) Regional Observatory for Epidemiology and was promoted by the regional division of the Italian Federation of Paediatricians. The study was conducted in accordance with Guideline for Good Clinical Practice and the ethical principles that have their origins in the Declaration of Helsinki. All participants were explained the purpose of the investigation and participation was voluntary and provided informed consent by e-mail.

\section{Results}

Of the 589 FPs operating in the Region, 218 (37\%) participated in the study (covering approximately 185,000 children); 7 FPs expressively refused to participate and 3 reported not to have any celiac patients, hence did not 
complete the questionnaire. Of the 218 respondents FPs, $57.3 \%$ were female, their median age was 54 years (range: 44-68; $1^{\circ}$ quartile: $50 ; 3^{\circ}$ quartile: 57 ) and they were from all the provinces of Puglia Region.

A total of 1,020 CD patients (representing approximately $1 \%$ of the children population covered by the participating FPs) were reported (an average of $5 \pm 3$ celiac patients per paediatrician). Of them, $55 \%$ were female; the mean of female patients for FP was higher than the male $(2.5 \pm 2.1$ vs $1.5 \pm 1.8 ; \mathrm{p}<0.0001) ; 45 \%$ of patients were aged from 5 to 10 years. Weight loss and stunting were the main reported symptoms at diagnosis $(41 \%)$, followed by anaemia (22\%), abdominal pain (19\%) and chronic diarrhoea $(17 \%$ - Table 1$)$.

Among the participating FPs, 90\% were those who first suspected CD in their patients. The vast majority (98\%) of FPs requested anti-tTG titres for the diagnosis of CD; antiEMA and anti-AGA titres were also requested (Table 2). Children were referred to a University Hospital (53\%), to a public hospital (44\%), and to another family paediatrician (3\%) for CD diagnosis. FPs that normally referred to a public hospital, reported a medium-high level difficulty in the diagnosis making process when programming for a biopsy for their patients compared to those FPs that referred to a University Hospital that reported no or a low level difficulty $(\mathrm{p}<0.0001)$.

Table 1 Distribution of celiac patients by sex, age group and clinical presentation at diagnosis, Puglia Region, 2012

\begin{tabular}{lcc}
\hline Characteristic & Number & $\%$ \\
\hline Sex & 556 & 54.5 \\
Female & 324 & 31.8 \\
Male & 140 & 13.7 \\
Missing & & \\
Age group & 16 & 1.6 \\
0-1 year & 201 & 19.7 \\
2-4 year & 457 & 44.8 \\
5-10 year & 206 & 20.2 \\
11-16 year & 140 & 13.7 \\
Missing & & \\
Clinical presentation at diagnosis & 418 & 41.0 \\
Weight loss and stunting & 225 & 22.1 \\
Anaemia & 198 & 19.4 \\
Recurrent abdominal pain & 170 & 16.7 \\
Chronic diarrhoea & 124 & 12.2 \\
Short stature & 47 & 4.6 \\
Asthenia & 43 & 4.2 \\
Hyper-transaminasemia & 41 & 4.0 \\
Constipation & 122 & 12 \\
Other symptoms & & \\
\hline
\end{tabular}

Table 2 Confirmatory tests for celiac disease required by family paediatricians, Puglia Region, 2012

\begin{tabular}{lc}
\hline Confirmatory test for celiac disease & $\%$ \\
\hline Anti-tissue transglutaminase antibody & 98.2 \\
Anti-endomysium antibody & 77.5 \\
Anti-gliadin antibody & 61.0 \\
Bowel biopsy & 25.2 \\
HLA DQ2 and DQ8 & 4.6 \\
Other tests & 17.4 \\
\hline
\end{tabular}

Of the 215 (99\%) responding to the question, 171 (78\%) FPs recommended gluten introduction in the diet of infants at the age of 6 months; $27(12 \%)$ and $17(8 \%)$ recommended introduction of gluten before and after 6 months of age respectively.

The number of celiac patients was higher among those FPs that recommended gluten introduction in the diet after 6 months of age compared to those who would recommend the introduction of gluten between 4 and 6 months of age ( $4.1 \pm 3.2$ vs $3.3 \pm 2.6, \mathrm{p}=0.1383)$.

The degree of knowledge for either $\mathrm{CD}$ diagnosis making process or CD related diseases was medium/high in $97 \%$ and $82 \%$ of the participating FPs respectively while it was low (37\%) for CD related psychological disorders (Table 3).

Almost $52 \%$ of the FPs were sometimes or often consulted for $\mathrm{CD}$ related diseases, followed by request of advices on CD related diet (39\% - Table 4).

The participating FPs had medium or no difficulty to provide their patients with dietary advice $(\sim 75 \%)$, communication and information on CD ( 66\%), and to follow their patients up ( 72\%) (Table 5).

FPs $(83 \%)$ who had a medium or high degree of knowledge of the diet for $C D$ patients were more likely to experience low or no difficulty in providing their patients with dietary advices (OR: 5.5, 95\% CI: 1.7-17.5; $\mathrm{p}<0.001-$ Table 6), and those (58\%) who had medium or high degree of knowledge of $\mathrm{CD}$ related diseases were sometimes or often consulted for these disease (OR: 2.2, 95\% CI: 0.9-5.2 $\mathrm{p}<0.05$ - Table 7).

Table 3 FPs self-reported degree of knowledge of celiac disease, Puglia Region, 2012

\begin{tabular}{lccccc}
\hline & \multicolumn{5}{c}{ Degree of knowledge } \\
\cline { 2 - 6 } & None & Low & Medium & High & Missing \\
\hline & $\mathrm{N}(\%)$ & $\mathrm{N}(\%)$ & $\mathrm{N}(\%)$ & $\mathrm{N}(\%)$ & $\mathrm{N}(\%)$ \\
CD diagnosis & $0(/)$ & $3(1.4)$ & $125(57.3)$ & $87(39.9)$ & $3(1.4)$ \\
Celiac diet & $1(0.5)$ & $17(7.8)$ & $152(69.7)$ & $17(7.8)$ & $2(0.9)$ \\
CD psychological & $10(4.6)$ & $80(36.7)$ & $99(45.4)$ & $21(9.6)$ & $8(3.7)$ \\
disorders & & & & & \\
CD related & $6(2.8)$ & $26(11.9)$ & $151(69.3)$ & $28(12.8)$ & $7(3.2)$ \\
diseases & & & & & \\
\hline
\end{tabular}


Table 4 FPs self-reported frequency of consultation for diet, psychological problems and diseases related to $C D$, Puglia Region, 2012

\begin{tabular}{lccccc}
\hline & \multicolumn{5}{c}{ Frequency of consultation } \\
\cline { 2 - 6 } & Never & Rarely & Sometimes & Often & Missing \\
\hline & $\mathrm{N}(\%)$ & $\mathrm{N}(\%)$ & $\mathrm{N}(\%)$ & $\mathrm{N}(\%)$ & $\mathrm{N}(\%)$ \\
Diet & $58(26.6)$ & $68(31.2)$ & $68(31.2)$ & $17(7.8)$ & $7(3.2)$ \\
$\begin{array}{l}\text { Psychological } \\
\text { problems }\end{array}$ & $77(35.3)$ & $59(27.1)$ & $60(27.5)$ & $15(6.9)$ & $7(3.2)$ \\
Related diseases & $48(22)$ & $45(20.6)$ & $86(39.4)$ & $27(12.4)$ & $12(5.5)$ \\
\hline
\end{tabular}

More than $60 \%$ of the FPs reported themselves as the reference point for the celiac patient, $34 \%$ partly, and $4 \%$ did not considered themselves as reference point.

Approximately $90 \%$ of the FPs defined useful to receive regular update on the disease and $12 \%$ of FPs reported to receive updates on gluten-free diet by the sales representatives.

\section{Discussion}

This is the first study evaluating the approach to diagnosis and management of celiac patient by family paediatricians in Italy.

Our findings show that FPs report a good degree of knowledge of $\mathrm{CD}$ related diseases and of gluten-free diet, although only a small proportion of them reported feeling comfortable with managing psychological disorders related to $\mathrm{CD}$.

The prevalence of $C D$ disease in our sample was consistent with other studies as well as the female to male ratio $[1,2,7,9,10]$.

Similarly to other Italian studies, FPs participating in our survey were more inclined to comply with the guidelines that recommend anti-tTG-Ab measurement as the elective

Table 5 FPs self-reported level of difficulty for programming a biopsy, for communication and information, and for dietary advice and any control or follow-up, Puglia Region, 2012

\begin{tabular}{lccccc}
\hline & \multicolumn{5}{c}{ Level of difficulty } \\
\cline { 2 - 6 } & $\begin{array}{l}\text { High } \\
\text { difficulty }\end{array}$ & $\begin{array}{c}\text { Medium } \\
\text { difficulty }\end{array}$ & $\begin{array}{c}\text { Low } \\
\text { difficulty }\end{array}$ & $\begin{array}{c}\text { No } \\
\text { difficulty }\end{array}$ & Missing \\
\hline & $\mathrm{N}(\%)$ & $\mathrm{N}(\%)$ & $\mathrm{N}(\%)$ & $\mathrm{N}(\%)$ & $\mathrm{N}(\%)$ \\
$\begin{array}{l}\text { Programming } \\
\text { a biopsy }\end{array}$ & $51(23.4)$ & $65(29.8)$ & $43(19.7)$ & $58(26.6)$ & $1(0.5)$ \\
$\begin{array}{l}\text { Communication } \\
\text { and information }\end{array}$ & $10(4.6)$ & $55(25.2)$ & $70(32.1)$ & $73(33.5)$ & $10(4.6)$ \\
$\begin{array}{l}\text { Dietary advice } \\
\text { Control or }\end{array}$ & $2(0.9)$ & $39(17.9)$ & $77(35.3)$ & $88(40.4)$ & $12(5.5)$ \\
follow-up & $3(1.4)$ & $46(21.1)$ & $74(33.9)$ & $84(38.5)$ & $11(5)$ \\
\hline
\end{tabular}

Table 6 Association (OR with 95\% Cl) between self-reported degree of knowledge and level of difficulty on providing advices on CD diet among the participating FPs, Puglia Region, 2012

\begin{tabular}{lcccccc}
\hline & \multicolumn{7}{c}{$\begin{array}{c}\text { Degree of knowledge } \\
\text { CD diet }\end{array}$} \\
\cline { 2 - 7 } & None/low & Medium/high & OR (95\% Cl) & X2 \\
\hline $\begin{array}{l}\text { Level of difficulty } \\
\text { advices on CD diet }\end{array}$ & $\mathrm{N}$ & $\%$ & $\mathrm{~N}$ & $\%$ & & \\
$\begin{array}{l}\text { No/low difficulty } \\
\text { Most/medium }\end{array}$ & 8 & 47.1 & 156 & 83.0 & $5.5(1.7-17.5)$ & 12.6 \\
difficulty & 9 & 52.9 & 32 & 17.0 & & \\
Total & 17 & - & 188 & - & & \\
\hline
\end{tabular}

screening test for patients with a suspect of CD [17]. The vast majority of our paediatricians requested this test when suspecting celiac disease from the clinical symptoms.

The diagnosis of $\mathrm{CD}$ is important not only in children with obvious gastrointestinal symptoms but also in children with a less clear clinical picture due to the progressive worsening of the health conditions and long-term sequelae $[15,28]$. In our study, most paediatricians were the first to have an early suspect of $\mathrm{CD}$ in their patients although they were probably missing the $\mathrm{CD}$ diagnosis in some children with atypical symptoms as the proportion of children typical symptoms was higher than what has been shown in screening studies.

Most of the FPs participating in the study would suggest the introduction of gluten in the diet between 4 and 6 months of age (reducing, possibly, the occurrence of $\mathrm{CD}$ ), similarly than in other countries where strong evidences suggest that solid food-items (including glutencontaining food) should be introduced in this age window $[19,21,29]$. Moreover, although not significant, a higher number of celiac patients was reported by those FPs who would suggest a gluten-containing diet after the age of 6 months. A higher risk of $C D$ is in fact shown among children who had been introduced with gluten in the diet

Table 7 Association (OR with $95 \% \mathrm{Cl}$ ) between self-reported degree of knowledge and frequency of consultation CD related diseases among the participating FPs, Puglia Region, 2012

\begin{tabular}{lcccccc}
\hline & \multicolumn{7}{c}{$\begin{array}{c}\text { Degree of knowledge } \\
\text { CD related diseases }\end{array}$} & & \\
\cline { 2 - 7 } & None/low & Medium/high & OR (95\% CI) & X2 \\
\hline $\begin{array}{l}\text { Frequency of } \\
\text { consultation CD } \\
\text { related diseases }\end{array}$ & $\mathbf{N}$ & $\%$ & $\mathbf{N}$ & $\%$ & & \\
Never/rarely & 19 & 61.2 & 72 & 42.1 & $2.2(0.9-5.2)$ & 3.9 \\
Sometimes/often & 12 & 38.7 & 99 & 57.9 & & \\
Total & 31 & - & 171 & - & & \\
\hline
\end{tabular}


in the first 3 months or after the 7th month of life compared with introducing gluten in the 4- to 6-month period [30].

The study showed the paramount role of family paediatricians in the identification and diagnosis of $\mathrm{CD}$ among their patients. Childhood is a challenging period for diagnosis and management of $\mathrm{CD}$ considering that the growth of the child and the development of the immune system is an on-going process. Thus, the understanding of the appropriate testing and the diagnostic approaches are crucial for the paediatrician when advising parents regarding the child's life-long gluten-free diet [15].

\section{Conclusion}

The degree of knowledge of $\mathrm{CD}$ (in particular on $\mathrm{CD}$ related diseases and CD associated diet needs) among our paediatricians was self-assessed and self-reported in the study. Self-assessment of the degree of knowledge was corroborated by the number of consultations that those FPs reported.

Our findings, however, do not reflect attitude and knowledge of all paediatricians in our Region, as less than a half of them participated in the study. Participation in the study could have been influenced by either lack of knowledge of the disease, or lack of celiac patients. Three paediatricians, who stated not having any celiac patients, completed the questionnaire up to the third question (i.e. how many children do you normally provide care to, and of these how many are celiac patients). Nevertheless, we will take advantage of diffusing the results of the study and the consequent recommendations to all paediatricians in the Region to involve as many as possible of them in future activities aiming to a better management of $\mathrm{CD}$.

Actions aiming to continuous education and emphasizing the importance of including information on $\mathrm{CD}$ in medical under and postgraduate trainings are crucial as the disease occurs often with systemic manifestation not involving only gastroenterology.

\section{Competing interests}

The authors declare that they have no competing interests.

\section{Authors' contributions}

FF conceived and designed the study, analyzed and interpreted data and contributed to draft the paper. MD participated in the design of the study and in the statistical analysis. CV and VA contributed to draw the study protocol and the questionnaire. PR and CT piloted the questionnaire. CP participated in the design of the study and acquisition of data. PR conceived the study, participated in its design and revised the manuscript. PB coordinated the study, interpreted data and revised the manuscript. All authors have given final approval of the version to be published.

\section{Acknowledgments}

The authors thank the regional section of Italian Federation of Paediatricians (FIMP) that supported the study and all the family paediatricians who participated in the survey.

The study was promoted by Puglia Regional Observatory for Epidemiology.

\section{Author details}

${ }^{1}$ Department of Medical and Surgical Sciences, University of Foggia, Viale Pinto, 71100 Foggia, Italy. ${ }^{2}$ Representatives of the Apulian Federazione Italiana Medici Pediatri (FIMP), Via S. Antonio 73, 70051 Barletta, Italy.

Received: 8 July 2013 Accepted: 17 February 2014 Published: 20 February 2014

\section{References}

1. Rashtak S, Murray JA: Review article: coeliac disease, new approaches to therapy. Aliment Pharmacol Ther 2012, 35(7):768-781.

2. Ravikumara M, Tuthill DP, Jenkins HR: The changing clinical presentation of coeliac disease. Arch Dis Child 2006, 91(12):969-971.

3. Martinelli D, Fortunato F, Tafuri S, Germinario CA, Prato R: Reproductive life disorders in Italian celiac women. A case-control study. BMC Gastroenterol 2010, 10:89.

4. Kneepkens CM, von Blomberg BM: Clinical practice: coeliac disease. Eur J Pediatr 2012, 171(7):1011-1021.

5. Mahadov S, Green PH: Celiac disease: a challenge for all physicians. Gastroenterol Hepatol (NY) 2011, 7(8):554-556.

6. Karandish E, Hachem C: Celiac disease. Mo Med 2009, 106(5s):346-350

7. Rossi M, Bot A: Celiac disease: progress towards diagnosis and definition of pathogenic mechanisms. Int Rev Immunol 2011, 30(4):183-184.

8. Berti I, Della Vedova R, Paduano R, Devetta M, Caradonna M, Villanacci V, Not T, Martelossi S, Tamburlini G, Ventura A: Coeliac disease in primary care: evaluation of a case-finding strategy. Dig Liver Dis 2006, 38(7):461-467.

9. Aggarwal S, Lebwohl B, Green PH: Screening for celiac disease in averagerisk and high-risk populations. Therap Adv Gastroenterol 2012, 5(1):37-47.

10. Megiorni F, Pizzuti A: HLA-DQA1 and HLA-DQB1 in Celiac disease predisposition: practical implications of the HLA molecular typing. J Biomed Sci 2012, 19:88.

11. Rubio-Tapia A, Kyle RA, Kaplan EL, Johnson DR, Page W, Erdtmann F, Brantner TL, Kim WR, Phelps TK, Lahr BD, Zinsmeister AR, Melton LJ 3rd, Murray JA: Increased prevalence and mortality in undiagnosed celiac disease. Gastroenterology 2009, 137:88-93.

12. Catassi C, Kryszak D, Bhatti B, Sturgeon C, Helzlsouer K, Clipp SL, Gelfond D, Puppa E, Sferruzza A, Fasano A: Natural history of celiac disease autoimmunity in a USA cohort followed since 1974. Ann Med 2010, 42:530-538.

13. Lohi S, Mustalahti K, Kaukinen K, Laurila K, Collin P, Rissanen H, Lohi O, Bravi E, Gasparin M, Reunanen A, Mäki M: Increasing prevalence of coeliac disease over time. Aliment Pharmacol Ther 2007, 26(9):1217-1225.

14. Nenna R, Tiberti C, Petrarca L, Lucantoni F, Mennini M, Luparia RP, Panimolle F, Mastrogiorgio G, Pietropaoli N, Magliocca FM, Bonamico M: The celiac iceberg: characterization of the disease in primary schoolchildren. J Pediatr Gastroenterol Nutr 2013, 56(4):416-421.

15. Steele R, Gibson P, Anderson R, Day A, Cameron D, Hogan C, Shepherd S, Price G, Dellsperger P, Steele R, Keuskamp G, Daveson J, Din JT: Diagnosis and management of coeliac disease in children. Postgrad Med J 2011, 87(1023):19-25.

16. Walker MM, Murray JA: An update in the diagnosis of coeliac disease. Histopathology 2011, 59(2):166-179.

17. Auricchio R, Granata V, Borrelli M, Troncone R, Italian Society for Pediatric Gastroenterology Hepatology and Nutrition (SIGENP): Italian paediatricians' approach to coeliac disease diagnosis. J Pediatr Gastroenterol Nutr 2009, 49(3):374-376

18. Husby S, Koletzko S, Korponay-Szabó IR, Mearin ML, Phillips A, Shamir R, Troncone R, Giersiepen K, Branski D, Catassi C, Lelgeman M, Mäki M, Ribes-Koninckx C, Ventura A, Zimmer KP, ESPGHAN Working Group on Coeliac Disease Diagnosis; ESPGHAN Gastroenterology Committee; European Society for Pediatric Gastroenterology, Hepatology, and Nutrition: European society for pediatric gastroenterology, hepatology, and nutrition guidelines for the diagnosis of coeliac disease. J Pediatr Gastroenterol Nutr 2012, 54(1):136-160. 18.

19. Agostoni C, Braegger C, Decsi T, Kolacek S, Koletzko B, Fleischer Michaelsen K, Mihatsch W, Moreno LA, Puntis J, Shamir R, Szajewska H, Turck D, van Goudoever J, ESPGHAN Committee on Nutrition: Breast-feeding: a commentary by the ESPGHAN committee on nutrition. J Pediatr Gastroenterol Nutr 2009, 49(1):112-125. 
20. European Food Safety Authority (EFSA), EFSA Panel on Dietetic Products, Nutrition and Allergies (NDA): Scientific opinion on the appropriate age for introduction of complementary feeding of infants. EFSA Journal 2009, 7:1423.

21. Agostoni C, Decsi T, Fewtrell M, Goulet O, Kolacek S, Koletzko B, Fleischer Michaelsen K, Moreno L, Puntis J, Rigo J, Shamir R, Szajewska H, Turck D, van Goudoever J, ESPGHAN Committee on Nutrition: Complementary feeding: a commentary by the ESPGHAN Committee on Nutrition. J Pediatr Gastroenterol Nutr 2008, 46:99-110.

22. N waru Bl, Erkkola M, Ahonen S, Kaila M, Happala AM, Kronberg-Kipilä C, Salmelin R, Veijda R, llonen J, Simmell O, Knip M, Virtanen SM: Age at the introduction of solid foods during the first year and allergic sensitization at age 5 years. Pediatrics 2010, 125:50-59.

23. Szajewska H, Chmielewska A, Pieścik-Lech M, Ivarsson A, Kolacek S, Koletzko S, Mearin ML, Shamir R, Auricchio R, Troncone R, PREVENTCD Study Group: Systematic review: early infant feeding and the prevention of coeliac disease. Aliment Pharmacol Ther 2012, 36(7):607-618.

24. Ivarsson A, Myléus A, Norström F, van der Pals M, Rosén A, Högberg L, Danielsson L, Halvarsson B, Hammarroth S, Hernell O, Karlsson E, Stenhammar L, Webb C, Sandström O, Carlsson A: Prevalence of childhood celiac disease and changes in infant feeding. Pediatrics 2013, 131(3):e687-e694.

25. Decreto del Presidente della Repubblica N. 272, art. 23: "Regolamento di esecuzione dell'accordo collettivo nazionale per la disciplina dei rapporti con i medici specialisti pediatri di libera scelta". Gazzetta Ufficiale della Repubblica Italiana N. 230; 2000. October 2th 2000.

26. Assistenza di base: il Pediatra di libera scelta. http://www.salute.gov.it/portale/ salute/p1_5.jsp?lingua=italiano\&id=58\&area=Servizi_al_cittadino_e_al_paziente.

27. Pediatra di libera scelta. http://www.salute.gov.ti/portale/temi/p2_6.jsp?

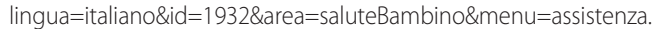

28. Rubio-Tapia A, Hill ID, Kelly CP, Calderwood AH, Murray JA, American College of Gastroenterology: ACG clinical guidelines: diagnosis and management of celiac disease. Am J Gastroenterol 2013, 108:656-676.

29. Guandalini S: The influence of gluten: weaning recommendations for healthy children and children at risk for celiac disease. Nestle Nutr Workshop Ser Pediatr Program 2007, 60:139-151. discussion 151-5.

30. Norris JM, Barriga K, Hoffenberg EJ, Taki I, Miao D, Haas JE, Emery LM, Sokol RJ, Erlich HA, Eisenbarth GS, Rewers M: Risk of celiac disease autoimmunity and timing of gluten introduction in the diet of infants at increased risk of disease. JAMA 2005, 293(19):2343-2351.

doi:10.1186/1471-230X-14-38

Cite this article as: Fortunato et al: Italian family paediatricians'

approach and management of celiac disease: a cross-sectional study in Puglia Region, 2012. BMC Gastroenterology 2014 14:38.

\section{Submit your next manuscript to BioMed Central and take full advantage of:}

- Convenient online submission

- Thorough peer review

- No space constraints or color figure charges

- Immediate publication on acceptance

- Inclusion in PubMed, CAS, Scopus and Google Scholar

- Research which is freely available for redistribution 